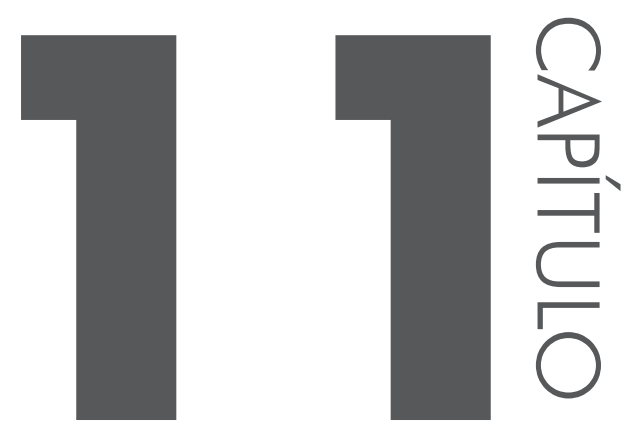

\title{
PROPOSTAS PARA INFORMATIZAC̣ÃO DE VIATURAS POLICIAIS COMO INSTRUMENTO DE SEGURANÇA PÚBLICA
}

Elbio Carlos Bock

Eliane Pozzebon

Luciana Bolan Frigo

\section{INTRODUC̣ÃO}

As viaturas policiais são elementos de uso mais efetivo para o desenvolvimento do trabalho policial. No Brasil, as viaturas possuem como equipamentos orgânicos as luzes de emergência e o rádio comunicador, servindo basicamente para o transporte de pessoal, sejam policiais ou pessoas envolvidas em ocorrências. Poucos são os estados que estão equipando suas viaturas com câmeras de vídeo e sistemas de captura de áudio.

Em outros países, como os Estados Unidos, as viaturas têm computadores, programas de registros de ocorrências, comunicação sem fio, entre outras tecno- 
logias. Seria uma alternativa como meio de aprimorar a segurança pública no Brasil, colaborando, em um segundo momento, com a manutenção do respeito aos Direitos Humanos.

Este trabalho elabora uma proposta de viatura policial equipada com tecnologia embarcada, que visa possibilitar um atendimento mais qualificado às ocorrências policiais, prestando melhor serviço à população brasileira, tanto em termos de segurança pública, quanto em Direitos Humanos. Para atingir este objetivo, foi realizado um levantamento com policiais civis e militares referente às necessidades de seu cotidiano quanto às tecnologias nas viaturas.

\section{METODOLOGIA}

Para chegarmos aos objetivos propostos, utilizou-se como metodologia a pesquisa literária, a fim de tomarmos conhecimento das novas tecnologias disponíveis no Brasil e em outros países, e uma pesquisa junto a policiais civis e militares, por meio de questionário, objetivando saber quais são as tecnologias atualmente disponíveis em suas viaturas e as tecnologias julgadas úteis para se chegar a um resultado mais efetivo no atendimento e na resolução das ocorrências policiais.

Após análise dos dados e informações obtidas, elaborou-se uma proposta de um protótipo de aplicação de tecnologia embarcada nas viaturas, que possibilite a dinamização dos trabalhos, com otimização de recursos e diminuição de tempo de atendimento das ocorrências policiais.

\section{ANÁLISE DA PESQUISA}

Para elaboração do presente trabalho, foi realizada uma pesquisa de campo, a partir da aplicação de um questionário a amostra de policiais civis e militares da cidade de Torres, no Rio Grande do Sul. A amostra consistiu em dez policiais militares, em um universo de 48 policiais, e dez policiais civis, em um universo de 22 policiais. Tal pesquisa visou, basicamente, ao levantamento de como são as viaturas policiais atualmente, quais tecnologias poderiam ser utilizadas para melhorar essas viaturas, e como os policiais imaginam que serão as viaturas no futuro, em um prazo de 20 anos.

As primeiras questões foram para conhecer a qual instituição pertencia o entrevistado e seu tempo de serviço naquela corporação (Gráfico 11.1). A quase totalidade dos policiais militares entrevistados contava com mais de 20 anos na função, variando de seis a 35 anos, ao passo que os policiais civis são, em média, mais jovens e com menos tempo de serviço, entre três a 22 anos de serviços prestados à corporação. 


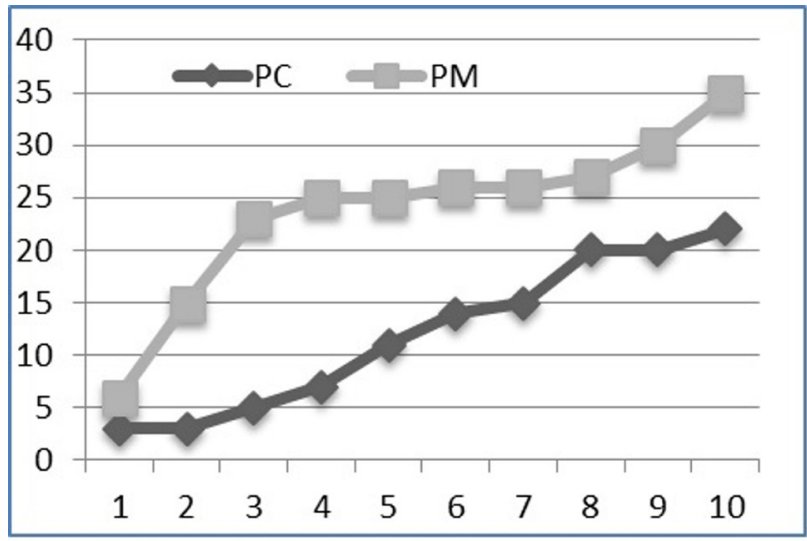

Gráfico 11.1 Instituições e tempo de serviço dos entrevistados.

Em se tratando do principal uso da viatura, elas são utilizadas para o policiamento ostensivo, atendimento de ocorrências e atividades administrativas por parte da Polícia Militar. Já os policiais civis mencionaram que a principal utilização é o transporte de presos e o serviço de investigação.

Todos os policiais entrevistados foram unânimes em afirmar, ao serem questionados sobre os equipamentos de suas viaturas, que elas apenas possuem rádio comunicador, sirenes e luzes de emergências (Gráfico 11.2). Houve uma menção à GPS por parte da Polícia Militar e uma por parte da Polícia Civil. Cabe salientar que, atualmente, cada corporação possui uma viatura com GPS integrante do kit multimídia original de fábrica de cada veículo, e não como acessório disponibilizado pelas corporações.

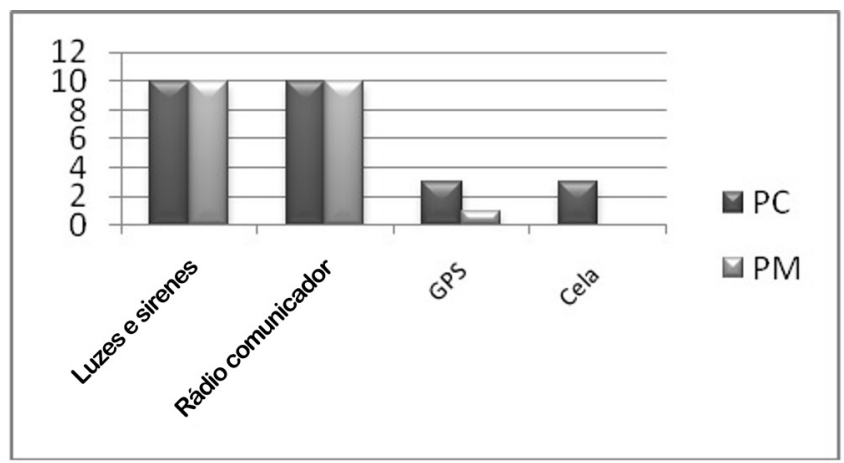

Gráfico 11.2 Equipamentos atualmente existentes nas viaturas.

Em contrapartida, ao serem questionados sobre quais meios julgavam úteis para suas funções, todos aqueles oferecidos como opções de respostas foram citados, sem exceção. Os policiais civis foram quase unânimes ao elenca- 
rem a totalidade dos itens de tecnologia, com apenas duas exceções do total de entrevistados. Já entre os policiais militares, houve uma variação maior, tendo, no entanto, igualmente todos os itens sido citados, com ênfase para rádio comunicador, leitor ótico para digitais, programa de reconhecimento facial, computador, cela e GPS.

Ao serem inquiridos acerca de quais tecnologias poderiam ser incluídas no futuro para melhorar as comunicações, os policiais, tanto civis quanto militares, fizeram menção aos dispositivos e programas como reconhecimento facial, escâner de placas etc. Além disso, conforme mostra o Gráfico 11.4, os policiais citaram que equipamentos de comunicação mais avançados passam, obrigatoriamente, por uma conexão sem fio de alta qualidade e velocidade de resposta. Também foi mencionado o uso de computadores com programas de consultas a indivíduos e veículos, que devem estar interligados a diversos bancos de dados em nível nacional.

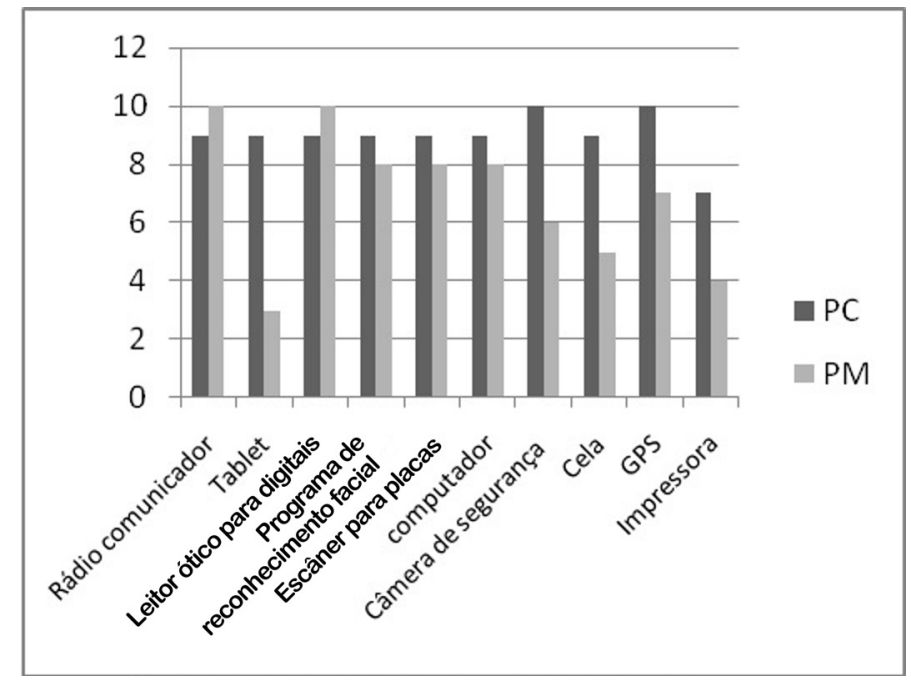

Gráfico 11.3 Equipamentos julgados úteis pelos policiais.

Questionados acerca da segurança das viaturas, mais especificamente sobre o que se poderia incluir nestas a fim de aumentar a segurança, a totalidade dos policiais militares mencionou a blindagem das viaturas como item mais importante a ser adotado. Citaram ainda o uso de armamento mais potente, do tipo fuzil, bem como computadores com sistemas avançados de consultas. Já os policiais civis, pela diversidade maior no uso das viaturas, mencionaram mais elementos ligados à tecnologia, como programas de identificação mais ágeis, sistemas de comunicação mais eficazes, celas e GPS em todas as viaturas. Mais da metade dos policiais civis entrevistados também mencionou a blindagem das viaturas como um item importantíssimo para sua segurança, conforme Gráfico 11.5. 


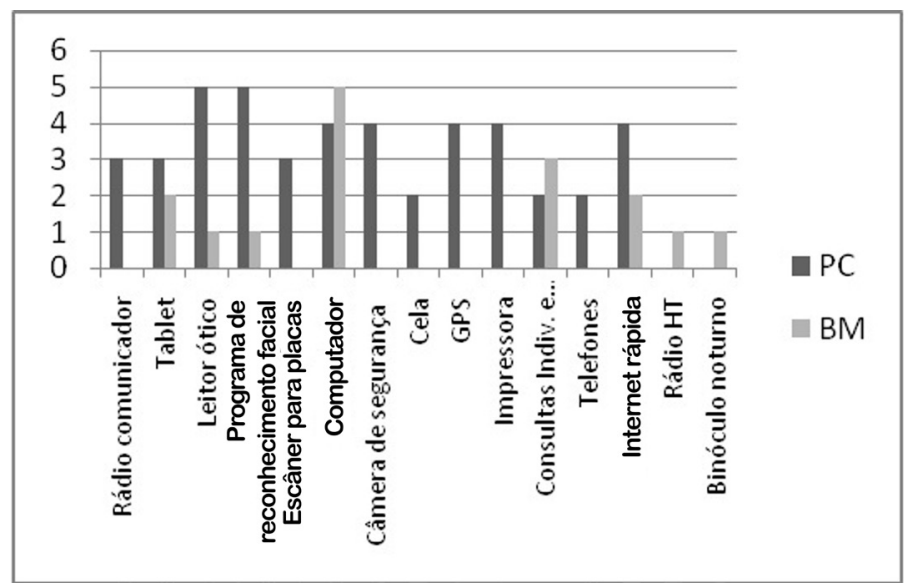

Gráfico 11.4 Tecnologias julgadas úteis em termos de comunicação.

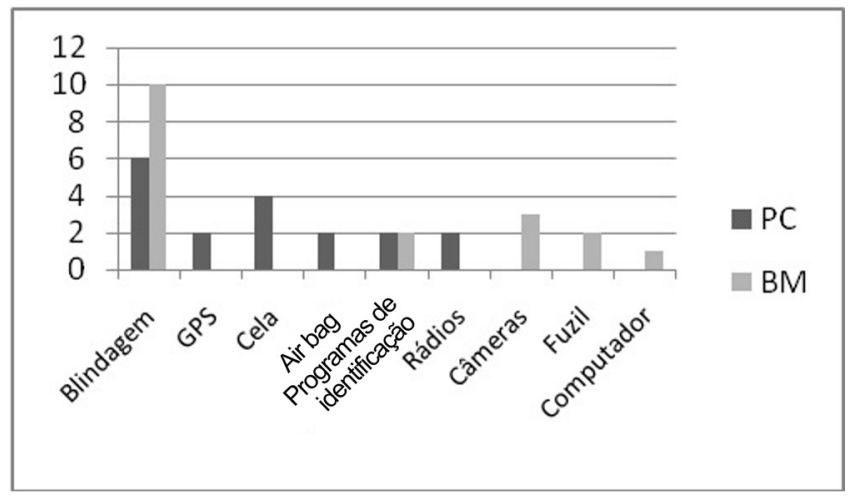

Gráfico 11.5 Tecnologias julgadas úteis para a segurança dos policiais.

A última questão foi a que causou maior surpresa e, ao mesmo tempo, preocupação pelas respostas obtidas. Embora tenham surgidos opiniões interessante, como veículos anfíbios, à prova de fogo, com blindagem máxima, flutuantes, motores potentes (sempre os melhores existentes no mercado), com tecnologia que forneça mais segurança aos policiais e aos suspeitos, com comunicação e sistemas de consultas eficazes, com identificação biométrica eficiente, também houve manifestações claras de desesperança em relação ao futuro.

$\mathrm{Na}$ polícia militar, cerca da metade dos entrevistados, e na polícia civil cerca de $30 \%$ dos consultados, manifestaram-se no sentido de não fazerem sequer uma previsão ou de ter ideia de como seriam as viaturas daqui a 20 anos.

Disso tudo, denota-se claramente a preocupação dos policiais com sua segurança pessoal, ao mencionarem majoritariamente a questão da blindagem das 
viaturas e uso de armamento mais potente, bem como se verifica o sentimento de abandono por parte do governo, ao relatar não terem perspectiva de melhora tecnológica, mesmo em uma visão no longo prazo.

\section{PROPOSTA DA VIATURA POLICIAL IDEAL}

Com base na análise da pesquisa de campo feita por meio de realização de questionário por amostragem junto às polícias civil e militar do Rio Grande do Sul, foi elaborada uma proposta de viatura de uso policial dotada de equipamentos que visam aperfeiçoar a eficiência das polícias, diminuir o tempo de atendimento às ocorrências, bem como reduzir os erros durante esse atendimento. Cabe esclarecer que nem todas as sugestões foram contempladas, eis que algumas delas são dignas de obra de ficção científica, inexequíveis em termos de realidade em um futuro próximo. Como exemplo disso, tivemos um caso de sugestão de viaturas que voassem/flutuassem ao invés de rodarem.

Da observância da situação atual das viaturas policiais no Brasil, além da análise de uma pequena amostra de como são as viaturas policiais na cidade de Fort Worth, no Texas, nos Estados Unidos, surgiu a ideia de como seria a viatura ideal para o uso em serviço policial, em termos de tecnologia da informação e comunicação, visando sua utilização de maneira mais eficaz, rápida e justa por parte das forças de seguranças nas suas mais variadas esferas. Para chegarmos a esse resultado, seria necessário que tais veículos fossem equipados com hardwares e softwares específicos para as atividades de segurança pública.

Em um primeiro momento, o veículo deverá ser equipado com um computador portátil, do tipo ultrabook, sendo este orgânico da viatura e ali permanecendo durante as 24 horas do dia. A recomendação é de que seja um equipamento com processador de altas capacidade e velocidade, com conexão à internet, o que facilitará as consultas a serem realizadas nos mais diversos bancos de dados em nível estadual e federal, devendo estes estar perfeitamente integrados e disponíveis para acessos remotos, como um notebook Getac B300 (GETAC, 2015).

A transmissão de dados se daria por meio do sistema wireless, ou seja, de ondas de rádio, sem a utilização de fios e, portanto, de maneira remota. Uma das preocupações em utilizar esse sistema é a segurança das transmissões, com a possibilidade da interceptação e captura desses dados e informações por terceiros. Atualmente, a utilização de criptografia é considerado um dos meios mais eficazes para garantir segurança na troca de mensagens, além da utilização de protocolos de segurança baseados nesses métodos. A criptografia transforma a mensagem utilizando uma cifra ou um sistema criptográfico, que codificam a mensagem de modo que este torne-se incompreensível. Desta maneira, existe uma chave (key), que funciona como uma senha para a cifra, que torna a mensagem incompreensível para todos 
menos para o emissor e receptor daquela mensagem, que terão acesso a essa chave e poderão decodificar aquela mensagem (DEITEL, et al. 2002).

Como um dos meios de entrada de dados, seriam utilizadas câmeras do tipo webcam, com autofoco e alta definição, para que possibilite a utilização dos softwares de detecção de placas e de reconhecimento facial. Tais câmeras permitiriam melhor qualidade de vídeo, por meio do controle automático, com cores vivas e imagens precisas (MAGYAR; SOUZA, 2014).

Um sistema para reconhecimento facial é composto por três momentos ou fases essenciais: mapeamento da face, captura e seleção de características faciais, e reconhecimento da face propriamente dito. Em um primeiro momento, as viaturas poderiam ser dotadas do software Malic - Reconhecimento Facial Open-Source.

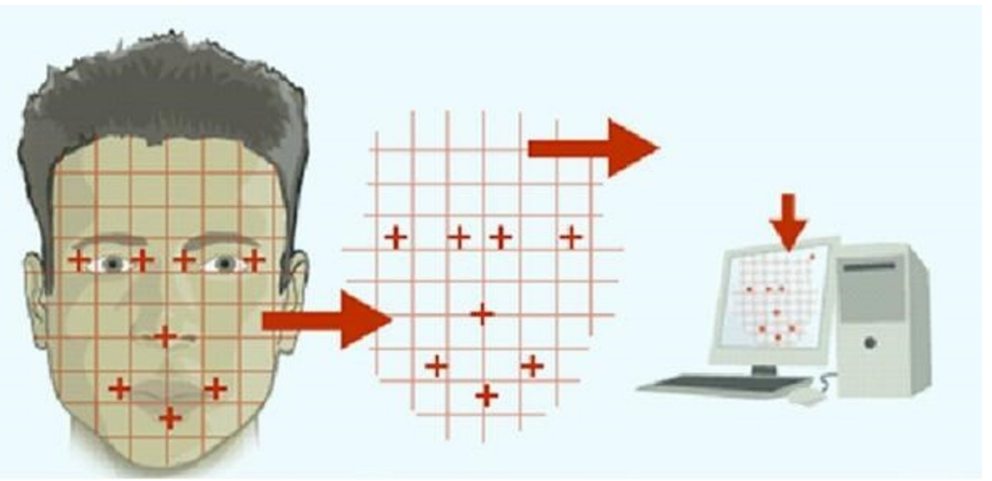

Figura 11.1 Representanção de captura da face.

Fonte: Tecmundo.com.br.

O primeiro passo é identificar, por meio de uma câmera (digital, webcam, de celular, entre outras), todos ou alguns desses pontos em comum, como os dois olhos e a distância entre eles, o nariz e seu comprimento, a boca, as bochechas e o queixo, limitando o formato da face e o espaço ocupado por ela (Figura 11.1). Esses pontos são gravados e armazenados no formato de algoritmos em um banco de dados, que os reconhecem a partir de cálculos. Uma vez feitos esses cálculos e reconhecida a face, essa imagem seria submetida a um banco de dados (inicialmente das polícias, institutos de identificação e Detrans) para fins de identificação do indivíduo, bem como de verificação de sua situação junto à Justiça.

Dentre os sistemas de leitura biométrica atualmente existentes, além do reconhecimento facial, outro de fundamental importância é o de leitura de impressão digital. Esse é um sistema que capta a imagem da impressão digital com um leitor biométrico óptico e compara com um banco de dados de imagens com as digitais gravadas. É um método rápido, de alta confiabilidade e baixo custo. E é justamen- 
te por essas garantias e facilidades em seu uso que entendemos ser perfeitamente possível seu uso em tecnologia embarcada em viaturas policiais.

\section{CONCLUSÕES}

No Brasil, não há uma cultura de valorização das polícias ou do serviço por elas prestados, justamente a começar pelos veículos disponibilizados. Por exemplo, na Alemanha, tem-se a cultura de que a polícia tem de estar equipada com melhores e mais potentes veículos do mercado. A explicação dada é, justamente, a valorização do policial. Segundo os alemães, se o policial vai abordar um veículo, que no Brasil seria considerado de luxo, ele não pode estar em situação inferior; ele tem de estar em pé de igualdade com o cidadão abordado, a fim de que não seja humilhado por este.

Por esta razão, entre outras, inclusive pelo desempenho de mais de 20 anos de serviço policial do autor deste artigo, vimos a necessidade de elaborar o presente trabalho, visando ser um marco na modernização das frotas policiais em operação em nosso país. A introdução de tal cultura serviria como instrumento de aprimoramento da prestação de uma função que é obrigação fundamental do Estado, qual seja o fornecimento de um serviço de excelência ao cidadão em termos de segurança.

Todas as tecnologias mencionadas, seja a identificação por reconhecimento facial, seja a identificação biométrica, apenas para citar as mais importantes, já são existentes. Bastaria que houvesse, por parte dos governantes, maior vontade política para melhorar os investimentos realizados nessa área, visto que, em um segundo momento, tais medidas gerariam economia aos cofres públicos. Tal afirmação segue este raciocínio: atualmente, tanto os estados quanto o Governo Federal são alvos de frequentes ações judiciais de indenização, oriundas de erros cometidos por seus agentes por meio de prisões irregulares e/ou ilegais, levando ao cárcere pessoas que não deveriam permanecer ali, justamente por erros de identificação.

Com a implementação das medidas apontadas neste trabalho, tais erros, se não eliminados, seriam reduzidos drasticamente, evitando, por consequência, um sem número de possíveis ações, que seriam fatalmente intentadas junto ao Poder Judiciário ante a manutenção dos moldes atuais das políticas de segurança pública, mais precisamente a utilização de meros veículos comuns, com pintura diferenciada e sirene e luz de emergência como únicos equipamentos disponíveis para abnegados servidores realizarem a segurança de qualidade a qual tanto necessita a nossa sociedade.

Como trabalhos futuros, poderiam ser estudadas novas formas de identificação, por exemplo, a leitura ótica da íris ou a identificação biométrica por meio da 
circulação sanguínea das veias das mão, que, assim como as digitais, são únicas nos indivíduos.

Agora, no campo de uma divagação, poder-se-ia também imaginar um incremento tecnológico para as viaturas utilizadas pelas equipes de perícias, para, quem sabe no futuro, podermos agilizar não só o atendimento das ocorrências diversas, mas igualmente sermos prodigiosos na realização de exames periciais. Quem sabe um furgão ou um utilitário com equipamentos e tecnologia que permitissem fornecer, em minutos e in loco, os tão aguardados resultados periciais, que hoje demoram de meses até mesmo anos para serem realizados e concluídos.

\section{REFERÊNCIAS}

BOCK, E. C. Sugestões para a informatização de viaturas policiais como instrumento de segurança pública. Pós-graduação em Tecnologias da Informação e Comunicação Aplicadas na Segurança Pública e Direitos Humanos. Universidade Federal de Santa Catarina. 2015. Disponível em: <http://posticsenasp.ufsc.br/files/2015/07/Dissertação_ Elbio-V13.pdf >. Acesso em: 1 fev. 2016.

DEITEL, H. M. et al. Wireless Internet and mobile business: how to program. Upper Saddle River: Prentice Hall, 2002. (Série How to Program).

GETAC. Descrição de computador Getac B300. Disponível em: <http://us.getac.com/ notebooks/B300/features.html>. Acesso em: 7 jun. 2015.

MAGYAR, A. M.; SOUZA, S. Y. Sistema de monitoramento e gravação para utilização em viaturas de policiamento ostensivo. Universidade Tecnológica Federal do Paraná. 2014. Disponível em: $<$ http://repositorio.roca.utfpr.edu.br/jspui/handle/1/2228>. Acesso em: 14 jul. 2015.

PASTORINI, A. Motorola traz viatura do futuro para a Interseg. Disponível em: $<$ http:// economiasc.com.br/wp-content/uploads/2014/09/carromotorola.jpg>. Acesso em: 9 jan. 2015. SOUZA, M. M. Siscompm: uma proposta de comunicação entre Copom e viaturas policiais militares utilizando comunicação wireless. Universidade Federal de Lavras. 2015. Disponível em: <http://repositorio.ufla.br/jspui/handle/1/9447>. Acesso em: 7 jun. 2015. 
